\title{
Pengaruh Profitabilitas, Pertumbuhan Perusahaan, Kebijakan Hutang, dan Likuiditas Terhadap Kebijakan Dividen Pada Perusahaan Manufaktur
}

\author{
Mas Intan Purba ${ }^{1}$, Juliana Lorent $^{2}$, Aditya Angga $^{3}$, Cynthia $^{4}$, Juli $^{5}$ \\ $1,2,3,4,5$ Universitas Prima Indonesia \\ email: ${ }^{1}$ masintanpurba84@ gmail.com, ${ }^{2}$ juliana.lorentz45@ gmail.com, ${ }^{3}$ aditya.angg0@ gmail.com, \\ cynthiaa2507@gmail.com, ${ }^{5}$ julitahm15@gmail.com

\begin{tabular}{ccc}
\hline Diterima & Direvisi & Disetujui \\
$10-02-2020$ & $21-02-2020$ & $02-03-2020$ \\
\hline
\end{tabular}

\begin{abstract}
Abstrak - Tujuan penelitian ini untuk menguji dan menganalisa pengaruh Profitabilitas, Pertumbuhan Perusahaan, Kebijakan Hutang, dan Likuiditas terhadap Kebijakan Dividen pada perusahaan manufaktur yang terdaftar di BEI tahun 2014-2017, baik secara parsial maupun secara simultan. Metode penelitian adalah penelitian deskriptif kuantitatif. Populasi ini adalah perusahaan manufaktur yang terdaftar di Bursa Efek Indonesia pada tahun 2017 yang berjumlah 156 perusahaan. Sampel dalam penelitian ini adalah 43 perusahaan yang diseleksi dengan kriteria tertentu. Metode statistik yang digunakan adalah analisis regresi linear berganda. Hasil penelitian menunjukkan bahwa Profitabilitas, Pertumbuhan Perusahaan dan Kebijakan Hutang berpengaruh signifikan terhadap Kebijakan Dividen. Sedangkan Likuiditas tidak berpengaruh dan tidak signifikan terhadap Kebijakan Dividen. Dan secara simultan Profitabilitas, Pertumbuhan Perusahaan, Kebijakan Hutang, dan Likuiditas berpengaruh signifikan terhadap Kebijakan Dividen. Besarnya koefisien determinasi sebesar 0,161 berarti bahwa hanya sebesar 16,1\% Kebijakan Dividen dapat dijelaskan Profitabilitas, Pertumbuhan Perusahaan, Kebijakan Hutang, dan Likuiditas, sedangkan sisanya sebesar 83,9\% dijelaskan oleh variabel lain yang tidak diteliti dalam penelitian ini seperti ukuran perusahaan dan struktur kepemilikan. Kesimpulan penelitian ini adalah secara parsial hanya Profitabilitas, Pertumbuhan Perusahaan dan Kebijakan Hutang, berpengaruh signifikan terhadap Kebijakan Dividen pada perusahaan manufaktur yang terdaftar di BEI tahun 2014-2017.
\end{abstract}

Kata Kunci : $\quad$ Profitabilitas, Pertumbuhan Perusahaan, Kebijakan Hutang, Likuiditas, Kebijakan Dividen

\begin{abstract}
The purpose of this study is to examine and analyze the effect of Profitability, Company Growth, Debt Policy, and Liquidity towards Dividend Policy on manufacturing companies listed on the IDX in 2014-2017, both partially and simultaneously. This study's method is quantitative descriptive study. These population are manufacturing companies listed on the Indonesia Stock Exchange in 2014-2017, amounting to 156 companies. The sample in this study are 43 companies selected with certain criteria. The statistical method used was multiple linear regression analysis. The results showed that profitability, company growth and debt policy significantly influence the dividend policy. Whereas Liquidity has no effect and insignificant on Dividend Policy. And simultaneously Profitability, Company Growth, Debt Policy, and Liquidity have a significant effect on Dividend Policy. The magnitude of the determination coefficient of 0.161 means that only $16.1 \%$ of the Dividend Policy can be explained Profitability, Company Growth, Debt Policy, and Liquidity, while the remaining $83.9 \%$ was explained by other variables not examined in this study such as company size and ownership structure. The conclusion of this study is that partially only Profitability, Company Growth and Debt Policy, significantly influence towards Dividend Policy on manufacturing companies listed on the IDX in 2014-2017.
\end{abstract}

Keywords: Company Growth, Debt Policy, and Liquidity towards Dividend Policy

\section{PENDAHULUAN}

Di era perekonomian pasar modal Indonesia yang telah berkembang pesat saat ini, banyak investor antusias untuk dapat menginvestasikan sebagian modalnya ke pasar modal Indonesia. Setiap perusahaan berusaha bersaing untuk menjadi lebih besar dengan cara menjalankan aktivitasaktivitasnya dengan efisien dan efektif agar investor dapat menginvestasikan modalnya. Akan tetapi untuk menarik perhatian investor bukan perkara mudah, karena perusahaan harus memperhatikan tingkat pengembalian return dalam bentuk dividen, karena investor tidak menyukai adanya risiko untuk mendapatkan laba yang besar dalam bentuk dividen.

Untuk menentukan besarnya dividen tunai diperlukan suatu kebijakan yang dinamakan kebijakan dividen. Kebijakan dividen 
menggambarkan keputusan untuk menentukan besarnya dividen yang dibayarkan untuk pemegang saham dan umumnya rasio ini diproksikan melalui Dividend Payout Ratio. Membagikan dividen tentunya melibatkan dua pihak yaitu pemegang saham dan perusahaan agar dapat menghasilkan keseimbangan antara dividen saat ini dan pertumbuhan di masa depan, karena hal ini berkaitan dengan beberapa rasio keuangan yaitu Profitabilitas, Pertumbuhan Perusahaan, Kebijakan Hutang dan Likuiditas.

Profitabilitas menunjukkan besarnya keuntungan yang diperoleh perusahaan selama satu periode. Profitabilitas ini diproksikan dengan Return On Equity (ROE). Apabila semakin besar profitabilitas (laba) yang dimiliki perusahaan semakin besar pula kebijakan dividen perusahaan sebaliknya semakin rendah laba yang dimiliki perusahaan maka semakin kecil kebijakan dividen perusahaan.

Pertumbuhan perusahaan memberitahukan adanya usaha untuk meningkatkan kelangsungan hidup perusahaan yang dapat dilihat dari aktiva perusahaan. Apabila pertumbuhan perusahaan mengalami peningkatan yang berarti laba ditahan meningkat maka kebijakan dividen justru mengalami penurunan dan sebaliknya pertumbuhan perusahaan mengalami penurunan yang berarti laba ditahan menurun maka kebijakan dividen justru semakin mengalami peningkatan.

Selain kedua variabel di atas, kebijakan hutang juga dapat mempengaruhi kebijakan dividen. Kebijakan hutang menunjukkan besar kemampuan perusahaan mengelola sumber dana. Kebijakan hutang diproksikan dengan Debt To Equity Ratio. Apabila semakin besar kebijakan hutang berarti semakin besar utang dan resiko yang akan dihadapi, sehingga adanya penurunan pada kebijakan dividen dan sebaliknya semakin kecil kebijakan hutang berarti semakin rendah utang dan resiko perusahaan, maka semakin besar kebijakan dividen perusahaan.

Variabel keempat diduga dapat mempengaruhi kebijakan dividen adalah likuiditas. Likuiditas menunjukkan besarnya hutang lancer yang segera jatuh tempo. Likuiditas ini diproksikan dengan Current Ratio. Apabila semakin besar likuiditas perusahaan berarti aset lancar lebih besar dari hutang lancar, sehingga kebijakan dividen akan mengalami peningkatan dan sebaliknya semakin kecil likuiditas perusahaan berarti aset lancar lebih kecil dari hutang lancar, sehingga kebijakan dividen akan mengalami penurunan. .

\section{Profitabilitas}

Menurut (A. S. M. Dewi \& Wirajaya, 2013), Profitabilitas merupakan analisis yang penting bagi kreditor yang karena dialokasikan untuk pembayaran bunga dan pinjaman dan bagi inverstor sebagai penentu perubahan nilai efek.

\section{Teori Pengaruh Profitabilitas Terhadap Kebijakan Dividen}

Menurut (Rais \& Santoso, 2017), perusahaan yang profitabilitasnya tinggi berarti tersedianya laba untuk dibagikan kepada pemegang saham. Laba tersebut akan digunakan untuk membayar dividen atau dialokasi sebagai laba ditahan oleh pemegang saham.

\section{Pertumbuhan Perusahaan}

Menurut (Setiawati \& Yesisca, 2016), pertumbuhan perusahaan merupakan usaha yang diupayakan agar adanya peningkatan ukuran perusahan.

\section{Teori Pengaruh Pertumbuhan Perusahaan Terhadap Kebijakan Dividen}

Menurut (Setiawati \& Yesisca, 2016), tingginya tingkat pertumbuhan perusahaan maka dana yang dibutuhkan juga semakin besar agar dapat mendanai perusahaan sehingga biasanya perusahaan mengalokasikan dana sebagai laba ditahan daripada membagi dalam bentuk dividen.

\section{Kebijakan Hutang}

Menurut (Thaib \& Taroreh, 2015), kebijakan hutang adalah dimana perusahaan berkemampuan dalam menggunakan pendanaan guna pelunasan hutang.

\section{Teori Pengaruh Kebijakan Hutang Terhadap Kebijakan Dividen}

Menurut (S. C. Dewi, 2008), kebijakan hutang berpengaruh negatif terhadap kebijakan dividen karena tingginya hutang maka dividen akan menurun karena keuntungan digunakan untuk melunasi hutang, tetapi jika hutang perusahaan rendah maka dividen akan meningkat.

\section{Likuiditas}

Menurut (Horne, James C. Van dan Wachowicz, 2012), rasio likuiditas adalah rasio yang mengukur usaha suatu perusahaan dalam memenuhi kewajiban yang harus segera lunasi.

\section{Teori Pengaruh Likuiditas Terhadap Kebijakan Dividen}

Menurut (Permana, Hendika Arga dan Hidayati, 2016), likuiditas dalam perusahan menujukan seberapa besar kekuatan perusahaan dalam memenuhi kewajiban jamgka pendeknya, sehingga terpenuhinya kegiatan perusahaan dalam membagikan dividen juga memperoleh rasa percaya investor terhadap kemampuan perusahaan membayar dividen yang dijanjikan.

\section{Kebijakan Dividen}

Menurut (Putra \& Lestari, 2016), kebijkan dividen adalah tentang seberapa mampunya suatu perusahaan dalam menggunakan laba baik diinvestasi maupun dibayarkan ke pemegang saham. 


\section{METODOLOGI PENELITIAN}

\section{Uji Asumsi Klasik}

1. Uji Normalitas

Menurut (Ghozali, 2016), uji normalitas memiliki tujuan menguji dalam model regresi, variabel pengganggu atau residual berdistribusi normal. Uji Normalitas ini dapat diuji menggunakan dua cara yaitu uji statistik dan analisis grafik.

\section{Uji Multikolinearitas}

Menurut (Ghozali, 2016), Uji multikolinearitas diperlukan untuk mengetahui apakah ditemukan adanya kemiripan antar variabel independen. Multikolinearitas diukur dengan nilai tolerance dan nilai Variance Inflation Factor (VIF), untuk menunjukan tidak adanya multikolinearitas adalah nilai Tolerance $>0.10$ atau sama dengan nilai VIF $<10$.

\section{Uji Autokorelasi}

Menurut (Ghozali, 2016), mengetahui autokorelasi bertujuan agar dapat menguji ada tidaknya korelasi antar variabel pengganggu periode tertentu dengan pengganggu periode sebelumnya. Untuk mendeteksi terjadi atau tidaknya autokorelasi, dapat digunakan uji Durbin Watson (DW).

\section{Uji Heteroskedastisitas}

Menurut (Ghozali, 2016), uji heteroskedasitas menguji apakah ada perbedaan variance dari residual suatu periode pengamatan ke periode pengamatan yang lain. Model regresi yang baik adalah yang homokedastisitas atau tidak terjadi heteroskedastisitas. Cara memprediksi ada tidaknya heteroskedastisitas yaitu melihat Grafik Scatterplot dan uji Park

\section{Metode Analisis Data Penelitian}

\section{Model Penelitian}

Analisis regresi linier berganda merupakan metode dari penelitian ini. Analisis regresi berganda bertujuan melihat besarnya arah koefisien atau hubungan antara variable independen dengan dependen. Model regresi yang digunakan adalah sebagai berikut:

$\mathrm{Y}=\mathrm{a}+\mathrm{b}_{1} \mathrm{X}_{1}+\mathrm{b}_{2} \mathrm{X}_{2}+\mathrm{b}_{3} \mathrm{X}_{3}+\mathrm{b}_{4} \mathrm{X}_{4}+\mathrm{e}$.

Keterangan :

$\begin{array}{ll}\mathrm{Y} & =\text { Kebijakan Dividen } \\ \mathrm{a} & =\text { Konstanta } \\ \mathrm{b}_{1} \ldots \mathrm{b}_{4} & =\text { Koefisienregresi } \\ \mathrm{X}_{1} & =\text { Profitabilitas } \\ \mathrm{X}_{2} & =\text { PertumbuhanPerusahaan } \\ \mathrm{X}_{3} & =\text { KebijakanHutang } \\ \mathrm{X}_{4} & =\text { Likuiditas } \\ \mathrm{e} & =\text { error (tingkat kesalahan) } 5 \%\end{array}$

\section{Koefisien Determinasi Hipotesis}

Menurut (Ghozali, 2016), nilai koefisien determinasi menujukan seberapa jauh kemampuan dalam menerangkan variasi variabel dependen. Menggunakan nilai adjusted $\mathrm{R}^{2}$ dalam menganalisa model regresi terbaik.

\section{Pengujian Hipotesis Secara Simultan (Uji F)}

Menurut (Sujarweni Wiratna, 2015), uji F digunakan untuk membuktikan pengaruh antara variabel independen terhadap variabel dependen secara simultan. Kriteria pengujian hipotesis secara simultan dapat dilakukan dengan dua cara yaitu :

Cara 1

a. Jika Sig > 0.05, maka $\mathrm{H}_{0}$ diterima dan $\mathrm{H}_{\mathrm{a}}$ ditolak.

b. Jika Sig $<0.05$, maka $\mathrm{H}_{0}$ ditolak dan $\mathrm{H}_{\mathrm{a}}$ diterima.

Cara 2

a. Jika $\mathrm{F}_{\text {hitung }}<\mathrm{F}_{\text {tabel }}$ maka $\mathrm{H}_{0}$ diterima dan $\mathrm{H}_{\mathrm{a}}$ ditolak.

b. Jika $\mathrm{F}_{\text {hitung }}>\mathrm{F}_{\text {tabel }}$ maka $\mathrm{H}_{0}$ ditolak dan $\mathrm{H}_{\mathrm{a}}$ diterima.

\section{Pengujian Hipotesis Secara Parsial (Uji t)}

Menurut (Sujarweni Wiratna, 2015), uji t menunjukan seberapa jauh pengaruh variabel independen secara parsial (individual) dalam menerangkan variabel dependen. Kriteria pengujian hipotesis secara parsial dapat dilakukan dengan dua cara yaitu:

Cara 1

a. Jika Sig >0.05, maka $\mathrm{H}_{0}$ diterima dan $\mathrm{H}_{\mathrm{a}}$ ditolak.

b. Jika $\mathrm{Sig}<0.05$, maka $\mathrm{H}_{0}$ ditolak dan $\mathrm{H}_{\mathrm{a}}$ diterima.

Cara 2

a. Jika $-\mathrm{t}_{\text {tabel }}<\mathrm{t}_{\text {hitung }}<\mathrm{t}_{\text {tabel }}$ maka $\mathrm{H}_{0}$ diterima dan $\mathrm{H}_{\mathrm{a}}$ ditolak.

b. Jika $t_{\text {hitung }}<-t_{\text {tabel }}$ dan $t_{\text {hitung }}>t_{\text {tabel }}$ maka $\mathrm{H}_{0}$ ditolak dan $\mathrm{H}_{\mathrm{a}}$ diterima.

\section{HASIL DAN PEMBAHASAN}

\section{Statistik Deskriptif}

Berikut statistik deskriptif yaitu:

Tabel 1. Statistik Deskriptf

Descriptive Statistics

\begin{tabular}{|c|c|c|c|c|c|}
\hline & \begin{tabular}{l|l}
$N$ & 1
\end{tabular} & Minimum & Maximum & Mean & \begin{tabular}{|c|} 
Std. \\
Deviation
\end{tabular} \\
\hline Profitabilitas & 172 & .0109 & 1.4353 & .190908 & .2492081 \\
\hline $\begin{array}{l}\text { Pertumbuhan } \\
\text { Perusahaan }\end{array}$ & 172 & -.1481 & 1.0305 & - 119137 & .1558825 \\
\hline $\begin{array}{l}\text { Kebijakan } \\
\text { Hutang }\end{array}$ & 172 & .0709 & 5.1524 & .758133 & .7774910 \\
\hline Likuiditas & 172 & .5139 & 15.1646 & 3.039787 & 2.4839862 \\
\hline $\begin{array}{l}\text { Kebijakan } \\
\text { Dividen }\end{array}$ & 172 & .0516 & 2.2414 & .442832 & .3356902 \\
\hline $\begin{array}{l}\text { Valid N } \\
\text { (listwise) }\end{array}$ & 172 & & & & \\
\hline
\end{tabular}

Sumber : Hasil Data Olahan SPSS 
Berdasarkan tabel statistik deskriptif pada variabel Profitabilitas menunjukkan nilai min sebesar 0,0109 terletak pada PT. Asahimas Flat Glass Tbk. di tahun 2017. Nilai max sebesar 1,4353 terletak di PT. Multi Bintang Indonesia Tbk. pada tahun 2014. Nilai mean tahun 2014-2017 sebesar 0,190908. Standart deviasi sebesar 0,2492081.

Statistik deskriptif pada variabel Pertumbuhan Perusahaan menjelaskan bahwa nilai min sebesar -0,1481 terletak di PT. Trisula International Tbk. pada tahun 2017. Nilai max sebesar 1,0305 terletak di PT. Tunas Alfin Tbk. pada tahun 2016. Nilai mean dari tahun 2014-2017 sebesar 0,119137, dan standart deviasi sebesar 0,1558825 .

Pada variabel Kebijakan Hutang statistik deskriptif memperlihatkan nilai min sebesar 0,0709 terletak di PT. Industri Jamu dan Farmasi Sido Muncul Tbk. pada tahun 2014. Nilai max sebesar 5,1524 terletak di PT. Indal Aluminium Industry Tbk. pada tahun 2014. Nilai mean tahun 2014-2017 sebesar 0,758133. Standart deviasi sebesar 0,7774910 .

Variabel Likuiditas pada statistik deskriptif menjelaskan bahwa nilai min sebesar 0,5139 terletak di PT. Multi Bintang Indonesia Tbk. pada tahun 2014. Nilai max sebesar 15,1646 terletak di PT. Duta Pertiwi Nusantara Tbk. pada tahun 2016. Nilai mean tahun 2014-2017 sebesar 3,039787. Standart deviasi sebesar 2,4839862.

Statistik deskriptif pada variabel Kebijakan Dividen menunjukkan nilai min sebesar 0,0516 terletak di PT. Wijaya Karya Beton Tbk. pada tahun 2014. Nilai max sebesar 2,2414 terletak di PT. Lion Metal Works Tbk. pada tahun 2017. Nilai mean tahun 2014-2017 sebesar 0,442832. Standart deviasi sebesar 0,3356902 .

Tabel 2. Hasil Uji Normalitas Dengan Kolmogorov Smirnov Setelah Outlier

One-Sample Kolmogorov-Smirnov Test

\begin{tabular}{|l|l|r|}
\hline \multicolumn{2}{|l|}{} & \multicolumn{1}{|l|}{$\begin{array}{l}\text { Unstandardized } \\
\text { Residual }\end{array}$} \\
\hline \multicolumn{2}{|c|}{$\mathrm{N}$} & 150 \\
\hline \multirow{2}{*}{ Normal Parameters ${ }^{\mathrm{a}, \mathrm{b}}$} & Mean & $0 \mathrm{E}-7$ \\
\cline { 2 - 3 } & Std. Deviation & .22640052 \\
\hline \multirow{3}{*}{ Most Extreme Differences } & Absolute & .105 \\
\cline { 2 - 3 } & Positive & .105 \\
\cline { 2 - 3 } & Negative & -.051 \\
\hline Kolmogorov-Smirnov Z & 1.287 \\
\hline Asymp. Sig. (2-tailed) & .073 \\
\hline
\end{tabular}

a. Test distribution is Normal.

b. Calculated from data.

Sumber : Hasil Data Olahan SPSS

Tabel Hasil Uji Normalitas Dengan Kolmogorov Smirnov Setelah Outlier menampilkan nilai Asymp. Sig. (2-tailed) sebesar 0,073 lebih besar dari 0,05 oleh karena itu data yang digunakan telah terdistribusi normal. Hasil statistik ini diperkuat dengan uji normalitas secara grafik yang dapat digambarkan sebagai berikut :

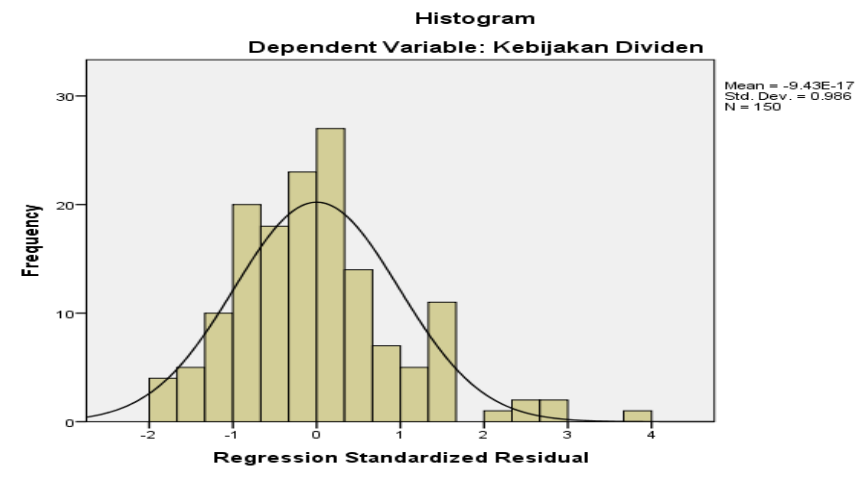

Sumber : Hasil Data Olahan SPSS

Gambar 1. Grafik Uji Normalitas

\section{Hasil Uji Normalitas Dengan Grafik Histogram Setelah Outlier}

Berdasarkan Grafik Uji Normalitas menunjukkan data distribusi tidak menceng ke kiri ataupun ke kanan seperti bentuk lonceng atau mengikuti garis kurva yang telah ditetapkan sehingga data telah terdistribusi secara normal.

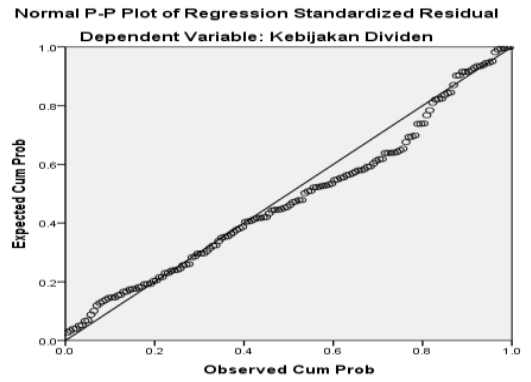

Sumber : Hasil Data Olahan SPSS

\section{Gambar 2. Grafik Normal Plot}

\section{Hasil Uji Normalitas Dengan Grafik Normal Plot Setelah Outlier}

Berdasarkan Grafik Normal Plot dapat terlihat titiktitik yang menyebar di sekitaran arah garis diagonal yang artinya pola data telah terdistribusi secara normal.

\section{Uji Multikolinearitas}

Dilakukan uji multikolinieritas dengan tujuan agar dapat mengetahui ada tidaknya kemiripan antara variabel independen dalam model regresi 
Tabel 3. Hasil Uji Multikolinearitas Setelah Outlier

\begin{tabular}{|c|c|c|c|c|c|c|c|}
\hline \multicolumn{8}{|c|}{ Coefficients $^{\mathrm{a}}$} \\
\hline \multirow[t]{2}{*}{ Model } & \multicolumn{2}{|c|}{$\begin{array}{c}\text { Unstandardized } \\
\text { Coefficients }\end{array}$} & \multirow{2}{*}{\begin{tabular}{|c|}
$\begin{array}{c}\text { Standardized } \\
\text { Coefficients }\end{array}$ \\
Beta \\
\end{tabular}} & \multirow[t]{2}{*}{$\mathrm{t}$} & \multirow[t]{2}{*}{ Sig. } & \multicolumn{2}{|c|}{$\begin{array}{l}\text { Collinearity } \\
\text { Statistics }\end{array}$} \\
\hline & $\mathrm{B}$ & $\begin{array}{l}\text { Std. } \\
\text { Error }\end{array}$ & & & & Tolerance & VIF \\
\hline (Constant) & .399 & .074 & & 5.362 & .000 & & \\
\hline Profitabilitas & .583 & .182 & .243 & 3.210 & .002 & .982 & 1.019 \\
\hline $\begin{array}{l}\text { Pertumbuhan } \\
\text { Perusahaan }\end{array}$ & -.374 & .165 & -.173 & -2.269 & .025 & .971 & 1.030 \\
\hline KebijakanHutang & -.119 & .056 & -.206 & -2.116 & .036 & .592 & 1.690 \\
\hline Likuiditas & .011 & .013 & .082 & .832 & .407 & .579 & 1.728 \\
\hline
\end{tabular}

Berdasarkan uji multikolinearitas setelah outlier, hasil uji multikolinearitas ini juga menunjukkan tidak terjadi gejala multikolinearitas antara setiap variabel independen (Profitabilitas, Pertumbuhan Perusahaan, Kebijakan Hutang, dan Likuiditas) yang dilihat dari nilai Tolerance lebih besar dari 0,1 juga nilai VIF lebih kecil dari 10.

\section{Uji Autokorelasi}

Menguji autokorelasi dalam regresi ditujukan untuk mengetahui ada tidaknya korelasi antara variabel pengganggu pada periode tertentu dengan variabel sebelumnya pada periode tertentu.

Gejala autokorelasi dapat diketahui dengan melakukan uji Durbin Watson (DW).

Tabel 4. Hasil Uji Autokorelasi Setelah Outlier

Model Summary ${ }^{\mathrm{b}}$

\begin{tabular}{|c|c|c|c|c|c|}
\hline Model & $\mathrm{R}$ & $\begin{array}{c}\mathrm{R} \\
\text { Square }\end{array}$ & $\begin{array}{c}\text { Adjusted R } \\
\text { Square }\end{array}$ & $\begin{array}{c}\text { Std. Error of } \\
\text { the Estimate }\end{array}$ & $\begin{array}{c}\text { Durbin- } \\
\text { Watson }\end{array}$ \\
\hline 1 & $.429^{\mathrm{a}}$ & .184 & .161 & .2295020 & 1.990 \\
\hline
\end{tabular}

a. Predictors: (Constant), Likuiditas, Profitabilitas,

Pertumbuhan Perusahaan, KebijakanHutang

b. Dependent Variable: KebijakanDividen

Sumber : Hasil Data Olahan SPSS

Berdasarkan Hasil Uji Autokorelasi Setelah Outlier diperoleh nilai Durbin Watson sebesar 1,990 dan tabel Durbin Watson dengan jumlah sampel sebesar 150 dan jumlah variabel independen sebanyak 4 maka diperoleh nilai batas bawah senilai 1,6788 serta batas atas senilai 1,7881 sehingga dari Tabel III.4 disimpulkan bahwa Durbin Watson bernilai 1,990 berada di du < d < 4-du atau 1,7881 < $1,990<2,2119$ berarti tidak ada masalah autokorelasi positif dan negatif.

\section{Uji Heteroskedastisitas}

Tujuan dari dilakukan uji herteroskedastisitas yaitu melihat apakah dalam model regresi terjadi perbedaan variance dari residual suatu periode pengamatan ke periode pengamatan lain.
Tabel 5. Hasil Uji Heteroskedastisitas Dengan Uji Glejser Setelah Outlier

Coefficients $^{\mathrm{a}}$

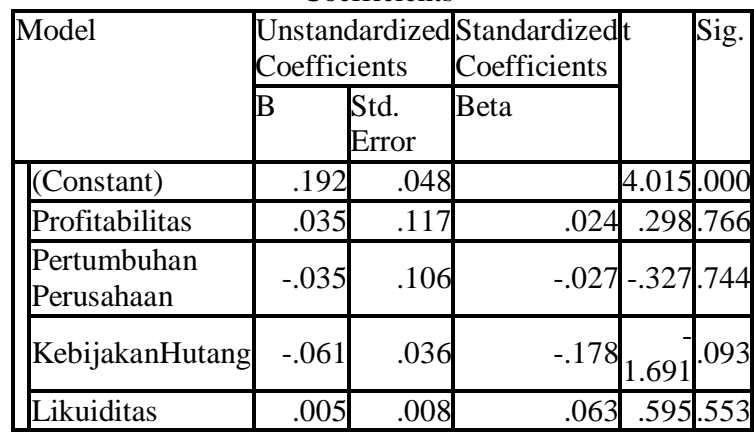

a. Dependent Variable: Absres2

Sumber : Hasil Data Olahan SPSS

Berdasarkan hasil uji heteroskedastisitas dengan uji glejser setelah outlier hasil uji glejser menunjukkan bahwa setiap variabel yaitu Profitabilitas, Pertumbuhan Perusahaan, Kebijakan Hutang, dan Likuiditas memiliki nilai signifikan lebih besar dari 0,05 , sehingga disimpulkan bahwa uji glejser ini tidak memiliki masalah heteroskedastisitas. Berikut hasil uji heteroskedastisitas dengan grafik scatterplot setelah outlier adalah sebagai berikut :

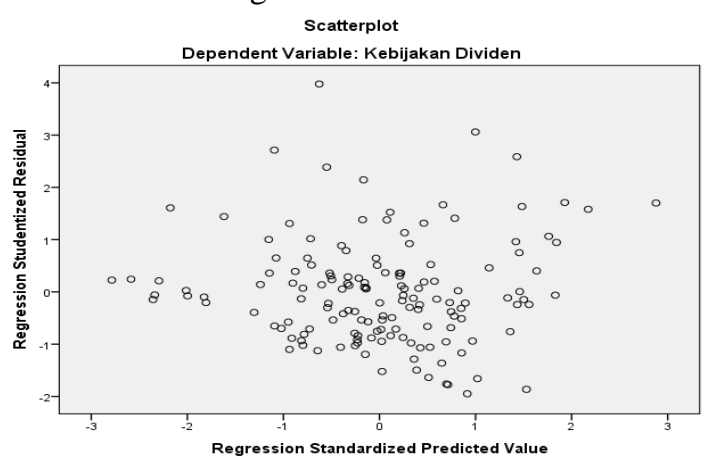

Sumber : Hasil Data Olahan SPSS

$$
\begin{aligned}
& \text { Gambar 3. Uji Heteroskedastisitas Dengan Grafik } \\
& \text { Scatterplot Setelah Outlier }
\end{aligned}
$$

\section{Hasil Uji Heteroskedastisitas Dengan Grafik Scatterplot Setelah Outlier}

Pada uji heteroskedastisitas dengan grafik scatterplot setelah outlier, grafik Scatterplot menunjukkan bahwa penyebaran residual tidak teratur sehingga titik-titik pola data menyebar dengan baik diatas juga di bawah angka nol pada sumbu Y.

\section{Model Analisis Data}

\section{Analisis Regresi Linear Berganda}

Analisis regresi linear berganda memiliki tujuan untuk melihat koefisien regresi yang ada pada pengaruh Profitabilitas, Pertumbuhan Perusahaan, Kebijakan Hutang, dan Likuiditas terhadap Kebijakan Dividen dapat dilihat pada Tabel ini. 
Tabel 6. Hasil Analisis Regresi Linear Berganda Coefficients $^{\mathrm{a}}$

\begin{tabular}{|l|r|r|r|r|r|}
\hline \multirow{2}{*}{ Model } & \multicolumn{2}{|c|}{$\begin{array}{c}\text { Unstandardized } \\
\text { Coefficients }\end{array}$} & $\begin{array}{l}\text { Standardized } \\
\text { Coefficients }\end{array}$ & \multirow{2}{*}{ Sig. } \\
\cline { 2 - 5 } & \multicolumn{1}{c|}{$\begin{array}{c}\text { B } \\
\text { Etd. }\end{array}$} & \multicolumn{1}{c|}{ Beta } & & \\
\hline Constant) & .399 & .074 & & 5.362 & .000 \\
\hline Profitabilitas & .583 & .182 & .243 & 3.210 & .002 \\
\hline $\begin{array}{l}\text { Pertumbuhan } \\
\text { Perusahaan }\end{array}$ & -.374 & .165 & -.173 & 2.269 & .025 \\
\hline KebijakanHutang & -.119 & .056 & -.206 & 2.116 & .036 \\
\hline Likuiditas & .011 & .013 & .082 & .832 & .407 \\
\hline
\end{tabular}

a. Dependent Variable: KebijakanDividen

Sumber : Hasil Data Olahan SPSS

Dari penelitian Hasil Analisis Regresi Linear Berganda ini maka model analisis regresi linear berganda dalam penelitian ini dirumuskan menjadi: Kebijakan Dividen $=0,399+0,583$ Profitabilitas 0,374 Pertumbuhan Perusahaan - 0,119 Kebijakan Hutang + 0,011 Likuiditas

Interepretasi dari persamaan regresi di atas adalah sebagai berikut:

a. Nilai konstanta (a) sebesar 0,399, artinya apabila Profitabilitas, Pertumbuhan Perusahaan, Kebijakan Hutang, dan Likuiditas bernilai nol atau konstan, maka Kebijakan Dividen terjadi kenaikan 0,399 satuan.

b. Koefisien regresi Profitabilitas sebesar 0,583 atau bersifat positif, berarti setiap kenaikan Profitabilitas senilai 1 satuan maka Kebijakan Dividen juga naik 0,583 satuan.

c. Koefisien regresi Pertumbuhan Perusahaan sebesar -0,374 atau bersifat negatif, artinya setiap kenaikan Pertumbuhan Perusahaan sebesar 1 satuan maka Kebijakan Dividen akan turun sebesar 0,374 satuan.

d. Koefisien regresi Kebijakan Hutang sebesar 0,119 atau bersifat negatif, artinya setiap kenaikan Kebijakan Hutang sebesar 1 satuan maka Kebijakan Dividen turun sebesar 0,119 satuan.

e. Koefisien regresi Likuiditas sebesar 0,011 atau bersifat positif, artinya setiap kenaikan Likuiditas sebesar 1 satuan maka Kebijakan Dividen naik sebesar 0,011 satuan.

\section{Koefisien Determinasi}

Digunakan koefisien determinasi intinya untuk mengetahui seberapa besar kemampuan model dalam menerangkan variasi variabel dependen.

Tabel 7. Hasil Uji Koefisien Determinasi Model Summary

\begin{tabular}{|r|r|r|r|r|}
\hline Model & R & R Square & $\begin{array}{c}\text { Adjusted R } \\
\text { Square }\end{array}$ & $\begin{array}{c}\text { Std. Error of } \\
\text { the Estimate }\end{array}$ \\
\hline 1 & $.429^{2}$ & .184 & .161 & .2295020 \\
\hline
\end{tabular}

a. Predictors: (Constant), Likuiditas, Profitabilitas, Pertumbuhan Perusahaan, Kebijakan Hutang

\section{Sumber : Hasil Data Olahan SPSS}

Hasil Uji Koefisien Determinasi menunjukan adjusted $R$ square bernilai 0,161 berarti bahwa hanya sebesar 16,1\% Kebijakan Dividen dapat dijelaskan Profitabilitas, Pertumbuhan Perusahaan, Kebijakan Hutang, dan Likuiditas, sisanya 83,9\% dijelaskan variabel lain yang tidak diteliti dalam penelitian ini misalnya ukuran perusahaan serta struktur kepemilikan.

\section{Pengujian Hipotesis Secara Simultan}

Pengujian ini menampilkan seluruh variabel independen yang signifikan pengaruhnya terhadap variabel dependen secara simultan.

Tabel 8. Hasil Uji F

ANOVA $^{\mathrm{a}}$

\begin{tabular}{|c|c|c|c|c|c|}
\hline Model & $\begin{array}{l}\text { Sum of } \\
\text { Squares }\end{array}$ & Df & $\begin{array}{c}\text { Mean } \\
\text { Square }\end{array}$ & $\overline{\mathrm{F}}$ & Sig. \\
\hline Regression & 1.719 & 4 & .430 & 8.157 & $.000^{6}$ \\
\hline Residual & 7.637 & 145 & .053 & & \\
\hline Total & 9.356 & 149 & & & \\
\hline
\end{tabular}

a. Dependent Variable: KebijakanDividen

b. Predictors: (Constant), Likuiditas, Profitabilitas, Pertumbuhan Perusahaan, Kebijakan Hutang

Sumber : Hasil Data Olahan SPSS

Hasil uji $\mathrm{F}$ yang ditampilkan menunjukkan bahwa nilai $F_{\text {hitung }} 8,157>F_{\text {tabel }} 2,43$ (Lampiran tabel statistik) dan signifikan $0,000<0,05$ sehingga hipotesis kelima diterima, artinya Profitabilitas, Pertumbuhan Perusahaan, Kebijakan Hutang, dan Likuiditas pengaruh positif dan signifikan terhadap Kebijakan Dividen pada perusahaan manufaktur yang terdaftar di BEI tahun 2014-2017.

\section{Pengujian Hipotesis Secara Parsial}

Dasar pengujian hipotesis secara parsial atau uji $t$ untuk melihat seberapa jauh pengaruh variabel independen secara parsial (individual) dalam menerangkan variabel dependen.

Tabel 8. Hasil Uji Statistik t

Coefficients $^{\mathrm{a}}$

\begin{tabular}{|c|c|c|c|c|c|}
\hline \multirow[t]{2}{*}{ Model } & \multicolumn{2}{|c|}{$\begin{array}{c}\text { Unstandardized } \\
\text { Coefficients }\end{array}$} & $\begin{array}{l}\text { Standardized } \\
\text { Coefficients }\end{array}$ & \multirow[t]{2}{*}{$\mathrm{t}$} & \multirow[t]{2}{*}{ Sig. } \\
\hline & $\bar{B}$ & $\begin{array}{l}\text { Std. } \\
\text { Error }\end{array}$ & Beta & & \\
\hline (Constant) & 399 & .074 & & 5.362 & .000 \\
\hline Profitabilitas & .583 & .182 & 243 & 3.210 & .002 \\
\hline \begin{tabular}{|l|} 
Pertumbuhan \\
Perusahaan
\end{tabular} & -.374 & .165 & -.173 & 2.269 & .025 \\
\hline KebijakanHutang & -.119 & .056 & -.206 & 2.116 & .036 \\
\hline Likuiditas & .011 & .013 & .082 & .832 & .407 \\
\hline
\end{tabular}

a. Dependent Variable: KebijakanDividen

Sumber : Hasil Data Olahan SPSS 
Data pada Hasil Uji Statistik t, maka hasil perhitungan statistik dengan program SPSS adalah sebagai berikut:

a. Variabel pertama yaitu Profitabilitas mempunyai nilai $t_{\text {hitung }}$ sebesar 3,210 $>t_{\text {tabel }}$ sebesar 1,976 (Lampiran tabel statistik) dan signifikan senilai $0,002<0,05$, dengan demikian hipotesis pertama diterima yang berarti Profitabilitas berpengaruh positif dan signifikan terhadap Kebijakan Dividen pada perusahaan manufaktur yang terdaftar di BEI tahun 2014-2017.

b. Variabel kedua yaitu Pertumbuhan Perusahaan mempunyai nilai $t_{\text {hitung }}$ sebesar $-2,269<-t_{\text {tabel }}$ sebesar -1,976 dan nilai signifikansi sebesar $0,025<0,05$, dengan demikian hipotesis kedua diterima yang berarti Pertumbuhan Perusahaan berpengaruh negatif dan signifikan terhadap Kebijakan Dividen pada perusahaan manufaktur yang terdaftar di BEI tahun 2014-2017.

c. Variabel ketiga yaitu Kebijakan Hutang mempunyai nilai $t_{\text {hitung }}$ sebesar $-2,116<-t_{\text {tabel }}$ sebesar $-1,976$ dan nilai signifikansi sebesar $0,036<0,05$, dengan demikian hipotesis ketiga diterima yang berarti Kebijakan Hutang berpengaruh negatif dan signifikan terhadap Kebijakan Dividen pada perusahaan manufaktur yang terdaftar di BEI tahun 2014-2017.

d. Variabel keempat yaitu Likuiditas mempunyai nilai $t_{\text {hitung }}$ sebesar $0,832<t_{\text {tabel }}$ sebesar 1,976 dan nilai signifikansi sebesar $0,407>0,05$, dengan demikian hipotesis keempat ditolak yang berarti Likuiditas tidak berpengaruh dan tidak signifikan terhadap Kebijakan Dividen pada perusahaan manufaktur yang terdaftar di BEI tahun 20142017.

\section{Pengaruh Profitabilitas Terhadap Kebijakan Dividen}

Hipotesis pertama yang diuji memperlihatkan nilai $\mathrm{t}_{\text {hitung }} 3,210>\mathrm{t}_{\text {tabel }} 1,976$ dan nilai signifikan $0,002<0,05$, dan disimpulkan hipotesis pertama diterima yang berarti Profitabilitas berpengaruh positif dan signifikan terhadap Kebijakan Dividen pada perusahaan manufaktur yang terdaftar di BEI tahun 2014-2017.

Hasil hipótesis ini sejalan dengan penelitian Komang Ayu (2014) yang menegaskan Profitabilitas berpengaruh positif dan signifikan terhadap Kebijakan Dividen.

\section{Pengaruh Pertumbuhan Perusahaan Terhadap Kebijakan Dividen}

Hipotesis kedua yang diuji memperlihatkan nilai $t_{\text {hitung }}-2,269<-t_{\text {tabel }}-1,976$ dan nilai signifikan $0,025<0,05$, disimpulkan hipotesis kedua diterima yang berarti Pertumbuhan Perusahaan berpengaruh negatif dan signifikan terhadap Kebijakan Dividen pada perusahaan manufaktur yang terdaftar di BEI tahun 2014-2017.
Hasil hipótesis seirama dengan penelitian (Setiawati\& Yesisca, 2016), yang menegaskan Pertumbuhan Perusahaan berpengaruh negatif dan signifikan terhadap Kebijakan Dividen.

\section{Pengaruh Kebijakan Hutang Terhadap} Kebijakan Dividen

Hipotesis ketiga yang diuji memperlihatkan nilai $t_{\text {hitung }}-2,116<-t_{\text {tabel }}-1,976$ dan nilai signifikan $0,036<0,05$, dengan demikian hipotesis ketiga diterima yang berarti Kebijakan Hutang berpengaruh negatif dan signifikan terhadap Kebijakan Dividen pada perusahaan manufaktur yang terdaftar di BEI tahun 2014-2017.

Hasil hipótesis seirama dengan penelitian ( $\mathrm{S}$. C. Dewi, 2008), yang menyampaikan Kebijakan Hutang berpengaruh negatif dan signifikan terhadap Kebijakan Dividen.

\section{Pengaruh Likuiditas Terhadap Kebijakan Dividen}

Hipotesis keempat yang diuji memperlihatkan nilai $t_{\text {hitung }} 0,832<\mathrm{t}_{\text {tabel }} 1,976$ dan nilai signifikan $0,407>0,05$, dengan demikian hipotesis keempat ditolak yang menunjukkan bahwa Likuiditas tidak berpengaruh dan tidak signifikan terhadap Kebijakan Dividen pada perusahaan manufaktur yang terdaftar di BEI tahun 2014-2017.

Hasil hipotes seirama dengan penelitian (Permana, Hendika Arga dan Hidayati, 2016), yang menyampaikan Likuiditas tidak berpengaruh dan tidak signifikan terhadap Kebijakan Dividen.

\section{KESIMPULAN}

Hasil penelitian dan pembahasan yang dikemukakan, maka yang dapat disimpulkan dari penelitian ini adalah :

1. Secara parsial, Profitabilitas berpengaruh positif dan signifikan terhadap Kebijakan Dividen pada perusahaan manufaktur yang terdaftar di BEI tahun 2014-2017.

2. Secara parsial, Pertumbuhan Perusahaan berpengaruh negatif dan signifikan terhadap Kebijakan Dividen pada perusahaan manufaktur yang terdaftar di BEI tahun 2014-2017.

3. Secara parsial, Kebijakan Hutang berpengaruh negatif dan signifikan terhadap Kebijakan Dividen pada perusahaan manufaktur yang terdaftar di BEI tahun 2014-2017.

4. Secara parsial, Likuiditas tidak berpengaruh dan tidak signifikan terhadap Kebijakan Dividen pada perusahaan manufaktur yang terdaftar di BEI tahun 2014-2017.

5. Secara simultan, Profitabilitas, Pertumbuhan Perusahaan, Kebijakan Hutang, dan Likuiditas berpengaruh positif dan signifikan terhadap Kebijakan Dividen pada perusahaan manufaktur yang terdaftar di BEI tahun 2014-2017. 
Hasil penelitian ini terdapat beberapa saran yang akan dikemukakan, yaitu:

1. Bagi peneliti

Harapan dari penelitian ini agar menambah wawasan yang dimiliki peneliti dan dapat digunakan dalam dunia usaha khususnya berkaitan dengan penelitian ini.

2. Bagi Universitas Prima Indonesia

Hasil penelitian diharapkan memberikan tambahan referensi bagi penelitian selanjutnya terutama yang berkaitan dengan Kebijakan Dividen.

3. Bagi investor atau calon investor

Harapan untuk memperhatikan variabel Profitabilitas, Pertumbuhan Perusahaan, Kebijakan Hutang yang berpengaruh secara signifikan terhadap Kebijakan Dividen ketika melakukan investasi di pasar modal

4. Bagi Peneliti Selanjutnya

Harapan agar menambah rasio keuangan lain seperti ukuran perusahaan dan struktur kepemilikan sebagai variabel independen, karena mungkin rasio keuangan lain yang tidak ada dalam penelitian ini berpengaruh terhadap Kebijakan Dividen.

\section{REFERENSI}

Dewi, A. S. M., \& Wirajaya, A. (2013). Pengaruh Struktur Modal , Profitabilitas Dan. E-Jurnal Akuntansi Universitas Udayana.

Dewi, S. C. (2008). PENGARUH KEPEMILIKAN MANAGERIAL ,. Jurnal Bisnis Dan Akuntansi.

Ghozali, I. (2016). Ghozali, Imam. (2016). Aplikasi Analisis Multivariate dengan Program IBM SPSS 23. Semarang: BPFE Universitas Diponegoro. IOSR Journal of Economics and Finance. https://doi.org/https://doi.org/10.3929/ethz-b000238666
Horne, James C. Van dan Wachowicz, J. M. (2012). Prinsip-prinsip Manajemen Keuangan. Edisi 13. Jakarta: Salemba Empat. https://doi.org/10.1016/j.neuroimage.2007.11. 048

Permana, Hendika Arga dan Hidayati, L. N. (2016). Analisis Pengaruh Leverage, Likuiditas, Profitabilitas, Pertumbuhan Perusahaan Dan Ukuran Perusahaan Terhadap Kebijakan Dividen Pada Perusahaan Manufaktur Yang Terdaftar Di Bei. Jurnal Manajemen Bisnis Indonesia (JMBI).

Putra, A. N. D. A., \& Lestari, P. V. (2016). Kebijakan Dividen, Likuiditas, Profitabilitas, Ukuran Perusahaan, Nilai Perusahaan. EJurnal Manajemen Unud.

Rais, bella novianti, \& Santoso, hendra F. (2017). pengaruh kepemilikan manajerial,kepemilikan institusioanl,profitabilitas dan ukuran perusahaan terhadap kebijakan deviden. Jurnal Ilmiah Manajemen Bisnis.

Setiawati, L. W., \& Yesisca, L. (2016). ANALISIS PENGARUH PERTUMBUHAN PERUSAHAAN, KEBIJAKAN UTANG, COLLATERALIZABLE ASSETS, DAN UKURAN PERUSAHAAN TERHADAP KEBIJAKAN DIVIDEN PADA PERUSAHAAN MANUFAKTUR YANG TERDAFTAR DI BURSA EFEK INDONESIA PERIODE 2012-2014. Jurnal Akuntansi. https://doi.org/10.25170/jara.v10i1.40

Sujarweni Wiratna. (2015). Metodologi Penelitian Bisnis dan Ekonomi. In Metodologi Penelitian. https://doi.org/10.1145/2505515.2507827

Thaib, C., \& Taroreh, R. (2015). Pengaruh Kebijakan Hutang dan Profitabilitas Terhadap Kebijakan Dividen. Jurnal EMBA. 